\begin{tabular}{|c|c|c|}
\hline 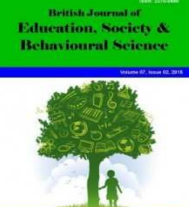 & $\begin{array}{c}\text { British Journal of Education, Society \& } \\
\text { Behavioural Science } \\
\text { 15(3): 1-11, 2016, Article no.BJESBS.25276 } \\
\text { ISSN: } 2278-0998\end{array}$ & SIENCEDOMAIN \\
\hline 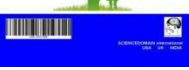 & $\begin{array}{l}\text { SCIENCEDOMAIN international } \\
\text { www.sciencedomain.org }\end{array}$ & \\
\hline
\end{tabular}

\title{
Measuring School Engagement: Validation and Measurement Equivalence of the Student Engagement Scale on Angolan Male and Female Adolescents
}

\author{
Melchor Gutiérrez $^{1^{*}}$, Jose M. Tomás ${ }^{2}$, Silvia M. Chireac ${ }^{3}$, Patricia Sancho ${ }^{4}$ \\ and Isabel Romero ${ }^{5}$
}

${ }^{1}$ Department of Educational and Developmental Psychology, Faculty of Psychology, University of Valencia, Spain.

${ }^{2}$ Department of Methodology for the Behavioral Sciences, Faculty of Psychology, University of Valencia, Spain.

${ }^{3}$ Language and Literature Teaching, Faculty of Teacher Training, University of Valencia, Spain.

${ }^{4}$ Department of Psychology and Sociology, Faculty of Social and Human Sciences, University of Zaragoza, Teruel, Spain.

${ }^{5}$ Departamento de Ciências da Educação, Instituto Superior de Ciências da Educação, Universidade Katyavala Bwila, Benguela, Angola.

\section{Authors' contributions}

This work was carried out in collaboration between all authors. Authors MG and JMT designed the study, wrote the protocol and supervised the work. Authors JMT and PS carried out the statistical analysis. Authors JMT and PS managed the analyses of the study. Authors MG, JMT and SMC wrote the first draft of the manuscript. Authors SMC and IR managed the literature searches and edited the manuscript. All authors read and approved the final manuscript.

\section{Article Information}

DOI: 10.9734/BJESBS/2016/25276 Editor(s):

(1) Shao-I Chiu, Taipei College of Maritime Technology of Center for General Education, Taiwan. Reviewers:

(1) Abilio Afonso Lourenco, Minho University, Braga, Portugal (2) Salome Schulze, University of South Africa, South Africa. Complete Peer review History: http://sciencedomain.org/review-history/14170

Original Research Article

Received $25^{\text {th }}$ February 2016 Accepted 26 $6^{\text {th }}$ March 2016 Published $14^{\text {th }}$ April 2016 


\section{ABSTRACT}

School engagement is defined primarily in relation to the participation of the student in academic achievement, and it is viewed as a multidimensional and integrative construct, or macroconstruct made up of several dimensions. The most repeated typology recognizes three specific dimensions: Cognitive, behavioral, and emotional (affective). Recently, a fourth new dimension, personal agency, has been proposed, which reflects students' constructive engagement with the academic instructions. F. Veiga has been the first to present a self-report instrument, in Portuguese, to measure these four components, the Student Engagement Scale-4 dimensions (SES-4DS). This research has studied the validity and reliability of this scale and its gender invariance in a sample of 2034 Angolan students. Results have shown a clear scalar invariant factor structure, some reliability problems, and adequate convergent and nomological validity. Latent differences were found between males and females for cognitive and affective engagement. Results are discussed in light of the existing literature.

Keywords: Emotional engagement; cognitive engagement; gender differences.

\section{INTRODUCTION}

Engagement in school settings is defined primarily in relation to the participation of the student in academic achievement, which leads "to the experiences and desired outcomes such as persistence, satisfaction, learning, and graduation" [1, p.44]. School engagement is viewed as a multidimensional and integrative construct, or macroconstruct, made up of several dimensions. There is no absolute consensus neither in the definition nor about what is the number of its dimensions but, at a minimum, engagement is seen as composed of participatory behavior and an affective component [2]. Other authors have added to this list a cognitive component or have divided the behavioral component into two dimensions, academic and behavioral or participation $[3,4,5]$. Nevertheless, the most repeated typology of dimensions of engagement recognizes three specific and overlapping dimensions: Cognitive, behavioral, and emotional $[4,6,7,8]$.

The cognitive dimension includes the use of sophisticated, deep and personalized learning strategies, seeking for conceptual understanding, and use of self-regulatory strategies $[5,9]$. It relies on students' investment in learning, encompassing intrinsic motivation and selfregulated metacognitive strategies used in tasks and learning activities as well as willingness to exert the necessary effort for comprehension of complex ideas [4]. The Behavioral dimension focuses on the students' persistence, consistency of effort, concentration, determination, involvement in academic tasks and extracurricular activities, actions and engagement; behavioral engagement; agency practices related to school and learning [10]. The emotional engagement or psychological dimension refers to students' attitudes about learning, teachers, academics and classmates and their feeling and sense of belonging to school and schoolwork [5].

Recently, a fourth new dimension, personal agency, has been proposed [11,12], which reflects students' constructive engagement with the academic instruction they receive at school. It is defined by an active, intentional, and constructive contribution into the flow of learning, as well as enriching the learning activity, rather than passively receiving information [9]. Hence, students' personal agency plays an important role in the school-related outcomes during their entire educational career. Personal agency makes the students active participants and valued partners in their classroom interactions. The cognitive, affective, behavioral and agentic components of school engagement are thought to be fully embedded within the individual and represent the way in which students act, feel and think at school [13].

Based on the four dimensional model of school engagement proposed by Reeve and Tseng [11], Veiga developed a self-report measure (the Student Engagement Scale-4 dimensions-SES4DS) to be used in Portuguese-speaking contexts. To our knowledge, Veiga's instrument has been the first scale in Portuguese to measure the three main components of student engagement (behavioral, emotional and cognitive) while adding the personal agency dimension. Items were derived from instruments developed in previous studies, a literature review 
and interviews with middle and high school students and their teachers [14-15]. Sentences were intended to be short and specific and were chosen to refer to the four aforementioned dimensions of engagement. Items tapping the behavioral dimension were derived from previous studies [16]. The affective dimension is composed of items employed in a new scale measuring student engagement in school, proposed to the PISA (Programme for International Student Assessment) project [15]. Cognitive engagement items were derived from studies on learning processes, and school motivation and academic time management [17]. Finally, the items sampling personal agency are based on several works [11,15]. Veiga [12] offers evidence on certain types of validity for the SES-4DS.

A number of variables/outcomes relevant in educational research have been linked to school engagement $[2,18,19]$, and therefore they are useful for validation purposes either as criteria or as a part of a nomological net. For example, teachers who promote students' autonomy also affect students' engagement by presenting interesting and relevant learning activities, providing optimal challenges, highlighting meaningful learning goals, and supporting students' volitional endorsement of classroom behaviors, according to the existing literature [20]. In the same vein, classroom environment is thought as playing an important role in students' motivation, engagement, and achievement at school. Researchers have suggested various ways to conceptualize the characteristics of classroom environments that would be related to students' adaptive engagement [21]. Among them, an influential framework has been achievement goal structures-students' perceptions of the motivational emphasis in their classroom [22,23]. As Ames [22] stated, mastery and performance goals represent different conceptions of success and different reasons for approaching and engaging in achievement activity, and involve different ways of thinking about oneself, one's task, and task outcomes. The term 'perceived motivational climate' refers to individual composite views regarding the situational emphasized goal structures operating in achievement settings. When success and failure are defined in comparison to the performance of others, a performance climate is stressed, but when self-referenced criteria of success are used, a mastery climate prevails [22]. The achievement goal structures that teachers emphasize play a critical role in how the school environment affects students' engagement [24].

Finally, school engagement has also been linked with satisfaction with school, and specifically, school satisfaction is thought to promote engagement. For example, Ladd, Buhs and Seid [25] found that kindergarten students' school satisfaction determined their subsequent school engagement behaviors. These results were also found by Elmore and Huebner [26]. Apparently, happiness, in the form of positive school satisfaction, and education are inextricably intertwined [27].

A bulk of research has been devoted to explore engagement differences between females and males. Martin [28] analyzed over 12,000 responses to the Motivation and Engagement Scale-High School (MES-HS), and females were found to be significantly higher than males in valuing of school, mastery orientation, planning, task management, and persistence, while males scored higher than females in their valuing selfhandicapping and disengagement. Indeed, students' level of engagement with their schools has been found to profoundly differ by gender. These differences have found empirical support regardless of the type of engagement studied [29]. However, most of these studies have not considered measurement equivalence when making gender comparisons [30], they took equivalence for granted. If measures of engagement are not gender invariant, it is inappropriate to compare levels of engagement across groups. For example, Betts, Appleton, Reschly, Christensenm and Scott-Huebner [31] tested for gender invariance and found a basic invariance both in factor loadings and residuals for males and females, but they failed to test for intercepts invariance. Wang, Willet and Eccles [32] tested the measurement invariance of behavioral, cognitive and emotional engagement in ninth grade students, across gender and race/ethnicity groups. Regarding gender invariance, they found measurement equivalence, and therefore tested for latent mean differences. They found significant differences favoring females in behavioral $(d=.32)$ and emotional engagement $(d=.25)$, whereas there were no significant differences in cognitive engagement across gender.

In the preface of an influential handbook on student engagement Christenson, Reschly and Wylie [33] argued that to date methodological rigor and psychometrically sound measurement 
of engagement has not yet completely been achieved. Although they recognize that there are engagement measures psychometrically sound, they also point out that further conceptual clarity and methodological rigor is needed in this arena. Thus, the aim of this research was threefold: a) to study the validity of the SES-4DS questionnaire, b) to analyze its measurement invariance across gender, and c) to study potential latent differences between male and female in student engagement.

\section{MATERIALS AND METHODS}

\subsection{Sample and Procedure}

The sample was composed of 2034 students studying seventh to twelfth grades in Angola. Their mean age was 17.5 years old $(S D=2.31)$. $48.9 \%$ were males $(n=993)$ and $50.1 \%$ were females $(n=1035)$. With respect to the grade they were studying: $7^{\circ}$ were $9.5 \%$; $8^{\circ}$ were $22.7 \%$; 9 were $39.5 \%$; 10을 were a $6.4 \%$; and finally $2.1 \%$ were studying the $12^{\circ}$ grade. $47.2 \%$ were living in rural areas, while the remaining $52.8 \%$ lived in urban areas. They were sampled in their school during normal teaching lessons. The survey was selfadministered but trained interviewers also were present to answer potential questions. Almost all participants completed the survey, but there were a few (less than 1\%) students who did not consistently answered all parts of the survey and their responses were deleted from further analyses. All ethical guidelines for research in Angola was accomplished and the required authorities' permissions were obtained. The students took about half an hour to answer the survey.

\subsection{Instruments}

The survey comprised several instruments on engagement and related topics, as well as basic socio-demographic information and academic achievement measures. All of them were rated as Likert-type ordinal measures from 1 (strongly disagree) to 5 (strongly agree). Among these instruments, the ones relevant for the validation of the engagement scales were:

a) Students' Engagement at School Scale- 4 dimensions (SES-4DS; [12]). A 20 items scale tapping four dimensions of engagement: Cognitive, affective, behavioral and agency. Each dimension has five indicators. b) Engagement [34]. A scale of five items measuring a single factor of students' perception of their attention, effort and participation in classroom activities.). Alpha in this sample was .73.

c) School satisfaction [34]. A scale of four items measuring a single factor with an alpha of .77.

d) Personal goal orientation and motivational climate [35]. A 15-item scale was used to assess personal goal orientation and perceptions of motivational climate. It comprised four dimensions, two of them measured goal orientations (mastery orientation and performance orientation), and the other two measured motivational climates (mastery climate and performance climate). Alphas for these four dimensions were, respectively: .65, .61, .60 and .56 .

e) Perceived autonomy support [36]. Students' perception of teachers-provided autonomy support was assessed with the six-item short version of the Learning Climate Questionnaire (LCQ, 37]). Alpha for this sample was .78.

There was a pilot study with 25 students to verify the adequate comprehension of all item contents.

\subsection{Statistical Analyses}

Main statistical analyses included a series of confirmatory factor analyses, the invariance routine to test for psychometric equivalence across sexes. The model specifies four latent variables (cognitive, affective, behavioral and agency engagement) each explaining five items. All models were estimated with EQS 6.1 [38]. Given non-normality of the data, maximum likelihood estimation with Satorra-Bentler corrections was used as recommended, for example, by Finney and Di Stefano [39].

The equivalence or invariance routine applied was the standard procedure [40]. This routine comprises a hierarchical set of steps. First, the model was separately tested on the two groups until good fit was achieved in both samples (males and females). Then, a configural model, with no parameter constraints across sexes, was tested simultaneously for females and males. This model tested the so-called weak factorial invariance or configural equivalence, and its fit indexes are used as the baseline fit criteria. Then, equality constraints were imposed for factor loading across groups, a constrained model that tests for metric invariance. 
Constrained item intercepts were added to the model with equal loadings subsequently, a model that tested for scalar invariance or strong factorial invariance. Finally, further equalities across gender were imposed on factor correlation. This last model does not test for psychometric invariance, it is of substantive interest. If this last model is tenable would give support to equality of correlations among the dimensions for males and females. No constraints for invariance of errors or factor variances were imposed (strict factorial invariance) as most researches omit these constraints as not really needed for mean comparisons [41].

The plausibility of the models was assessed using several fit criteria [42,43]: (a) chi-square statistic $[44,45]$; (b) the comparative fit index (CFI; [46]) of more than .90 (and, ideally, greater than .95; [42]); and (c) the root mean squared error of approximation (RMSEA) of .08 or less (and, ideally less, than .05) [42]. Hu and Bentler's [42] suggested that a CFI of at least .90, and a RMSEA less than .06 together, would indicate a very good fit between the hypothesized model and the data. The models in the invariance routine are nested. When nested models are compared there are two rationales [47]: The statistical and the modeling one. The statistical approach employs $\chi^{2}$ differences $\left(\Delta \chi^{2}\right)$ to compare constrained to unconstrained models, with non-significant values suggesting multigroup equivalence or invariance. This statistical approach has been criticized $[47,48]$, recommending the modeling approach that uses practical fit indices to determine the overall adequacy of a fitted model. From this point of view, if a parsimonious model (such as the ones that posit invariance) evinces adequate levels of practical fit, then the sets of equivalences are considered a reasonable approximation to the data. Usually, $\mathrm{CFI}$ differences $(\triangle \mathrm{CFI})$ are used to evaluate measurement invariance. $\mathrm{CFI}$ differences lower than .01 [48] or 0.05 [47] are usually employed as cut-off criteria.

\section{RESULTS}

\subsection{Measurement Invariance}

The a priori four-factor model was separately estimated and tested in Angolan males and females data. This model included four dimensions with five balanced items for each one. This four-factor model did not adequately fit the data neither for females $\left(\chi^{2}(164)=553.52\right.$, $p<.001, \mathrm{CFI}=.832, \mathrm{RMSEA}=.049,90 \% \mathrm{Cl}$ $[.044-.058])$ nor for males $\left(\chi^{2}(164)=649.21\right.$, $p<.001, \mathrm{CFI}=.839, \mathrm{RMSEA}=.053,90 \% \mathrm{Cl}$ [.049 - .053]). A close look at factor loadings made clear that two items (2 and 18) in the affective dimension did not load well on this factor for both samples. They were removed and the model estimated and tested again in both samples. The fit was adequate for both samples: females $\left(\chi^{2}(129)=263.02, p<.001, \mathrm{CFI}=.94\right.$, RMSEA $=.032,90 \% \mathrm{Cl}[.026-.037])$ and males $\left(\chi^{2}(129)=267.70, p<.001, \mathrm{CFI}=.94, \mathrm{RMSEA}=\right.$ $.033,90 \% \mathrm{Cl}[.027-.038])$. Descriptive statistics for the 20 items for males and females are presented in Table 1, including the mean, standard deviation, skewness, and kurtosis.

Once the adequate fit of both samples was achieved, the set of increasingly constrained multi-group models were estimated and tested. Table 2 shows the sequence of models, their fit indices and their chi-square and CFI differences to baseline (configural) model. Both statistical and practical approaches to model comparison agree that there were no statistically significant differences between configural, metric and scalar equivalent models, and therefore the more parsimonious (scalar with equal correlations) model could be retained. Indeed practical fit indices remained extremely similar or even slightly improved (i.e. the RMSEA). Accordingly, the set of equivalences were considered tenable, and the SES-4DS may be considered equivalent by gender.

Unstandardized and standardized factor loadings in the retained model are presented in Table 3. Table 4 offers covariances and correlations among the four dimensions of engagement for both groups. In general there are significant correlations among all dimensions. Once scalar equivalence was established the latent means differences could be investigated. The latent mean values were fixed to zero for females, making them the reference group. Males had higher ratings in cognitive engagement than females $(\alpha=0.063, z=2.46, p<.05, d=0.33)$, and they also had higher ratings in affective engagement than females $(\alpha=0.108, z=2.76$, $p<.05, d=0.24)$. There were no significant mean differences neither in behavioral $(\alpha=$ $0.004, z=.127, p>.05, d=0.01)$ nor in agency engagement $(\alpha=0.052, z=1.65, p>.05$, $d=0.17)$. 
Table 1. Means, standard deviations, skewness and kurtosis for the original 20 items in the SES-4DS

\begin{tabular}{|c|c|c|c|c|c|c|c|c|}
\hline \multirow[t]{2}{*}{ Item } & \multicolumn{4}{|c|}{ Females } & \multicolumn{4}{|c|}{ Males } \\
\hline & Mean & SD & Skewness & Kurtosis & Mean & SD & Skewness & Kurtosis \\
\hline 1 & 3.16 & 1.291 & -.272 & -1.101 & 3.23 & 1.291 & -.398 & -.997 \\
\hline 2 & 2.34 & 1.297 & .690 & -.692 & 2.21 & 1.233 & .824 & -.401 \\
\hline 3 & 1.95 & 1.110 & 1.224 & .787 & 1.88 & 1.078 & 1.311 & 1.091 \\
\hline 4 & 3.72 & 1.090 & -.827 & .066 & 3.77 & 1.092 & -.894 & .231 \\
\hline 5 & 3.69 & 1.141 & -.836 & -.089 & 3.76 & 1.102 & -.919 & .183 \\
\hline 6 & 3.63 & 1.281 & -.663 & -.715 & 3.81 & 1.169 & -.854 & -.161 \\
\hline 7 & 1.99 & 1.152 & 1.130 & .386 & 2.04 & 1.192 & 1.055 & .178 \\
\hline 8 & 2.71 & 1.279 & .268 & -1.065 & 2.77 & 1.331 & . 199 & -1.173 \\
\hline 9 & 3.15 & 1.237 & -.205 & -.972 & 3.25 & 1.274 & -.313 & -.975 \\
\hline 10 & 3.69 & 1.148 & -.773 & -.203 & 3.77 & 1.133 & -.919 & .161 \\
\hline 11 & 1.97 & 1.182 & 1.210 & .512 & 1.97 & 1.200 & 1.145 & .276 \\
\hline 12 & 3.68 & 1.100 & -.831 & -.067 & 3.70 & 1.179 & -.846 & -.166 \\
\hline 13 & 4.04 & 1.020 & -1.247 & 1.176 & 4.08 & 1.033 & -1.426 & 1.803 \\
\hline 14 & 3.56 & 1.191 & -.539 & -.642 & 3.64 & 1.148 & -.700 & -.243 \\
\hline 15 & 1.86 & 1.084 & 1.326 & 1.012 & 1.91 & 1.180 & 1.225 & .497 \\
\hline 16 & 3.44 & 1.150 & -.566 & -.531 & 3.47 & 1.189 & -.622 & -.517 \\
\hline 17 & 3.36 & 1.171 & -.466 & -.619 & 3.50 & 1.202 & -.563 & -.590 \\
\hline 18 & 2.14 & 1.202 & 1.030 & .190 & 2.18 & 1.212 & .860 & -.229 \\
\hline 19 & 2.22 & 1.121 & .711 & -.276 & 2.20 & 1.187 & .773 & -.333 \\
\hline 20 & 3.45 & 1.219 & -.512 & -.721 & 3.55 & 1.215 & -.627 & -.553 \\
\hline
\end{tabular}

Table 2. Set of hierarchical models to test for gender measurement invariance

\begin{tabular}{|c|c|c|c|c|c|c|c|c|}
\hline Model & ${ }_{\mathrm{SB}} \chi^{2}$ & df & $\Delta_{\mathrm{SB}} \chi^{2}$ & $p$ & CFI & $\Delta \mathrm{CFI}$ & RMSEA & $90 \% \mathrm{Cl}$ \\
\hline $\begin{array}{l}\text { Configural equivalence } \\
\text { (baseline) }\end{array}$ & 530.73 & 258 & -- & -- & .934 & & .032 & $.028-.036$ \\
\hline Metric equivalence & 543.42 & 276 & 9.47 & $>.05$ & .936 & .002 & .031 & $.027-.035$ \\
\hline Scalar equivalence & 562.01 & 286 & 25.9 & $>.05$ & .935 & .001 & .032 & $.028-.035$ \\
\hline $\begin{array}{l}\text { Scalar and equal factor } \\
\text { correlation }\end{array}$ & 574.24 & 292 & 39.2 & $>.05$ & .933 & .001 & .032 & .028-.035 \\
\hline
\end{tabular}

Notes: ${ }^{*} p<.05 ; s B \chi^{2}=$ Satorra-Bentler chi-square; $d f=$ degrees of freedom; $\Delta=$ differences

\subsection{Reliability and Nomological Validity}

Alphas were $.60, .60, .72$ and .58 respectively for the dimensions of cognitive, affective, behavioral and agency engagement. With respect to the criterion-related and nomological validity, Table 5 offers the correlations with the criterion and the nomological net of constructs. All these correlations were in the hypothesized direction and may be considered adequate.

\section{DISCUSSION}

The SES-4D is, to our knowledge, the only scale in Portuguese language that measures the three common dimensions of school engagement (cognitive, behavioral and affective), plus the recently proposed new dimension of agency or agentic engagement [11]. Veiga [12] presented an initial validation of the scale, but an independent replication has never been presented and measurement invariance across gender has not yet been tested. Therefore, a validation of the scale in a sample coming from a different population seems timely. Reliability, factorial, criterion-related and nomological validity results of the SES-4DS in a large sample of Portuguese-speaking Angolan students is presented. Additionally, measurement invariance across gender is stablished and males' and females' engagement means compared at the latent level. This research is based on a Portuguese-speaking population coming from a very different cultural context to the original applications of the scale, and it can be therefore considered a cross-cultural validation.

With respect to factorial validity, a good model fit was achieved for the scale, with a structure of the aforementioned four dimensions, but only 
after deleting two items in the affective dimension ("My school is a place where I feel excluded", "My school is a place where I feel alone"). It is worth noting that these two items, with an inadequate psychometric behavior, were the only ones negatively worded in the affective dimension. This structure was found to be scalar invariant for males and females. That is, the main psychometric properties remain the same for males and females, which is important for further gender comparisons. Criterion-related and nomological validity of the four dimensions of engagement can be considered adequate, with all of the relationships in accordance to hypotheses. Internal consistency, as estimated by Cronbach's alphas, cannot be considered adequate as three of the four dimensions had alphas around or equal to .60.

This results should be compared to those in the literature. Although validity results can be compared to the broad literature on engagement, regardless of the specific scale used (for example, engagement has been systematically related to teachers' autonomy support), reliability comparisons can only be made within the same

Table 3. Item content, hypothesised factor, unstandardized and standardized factor loadings

\begin{tabular}{lllll}
\hline Item & Factor & UE & SEf & SEm \\
\hline 1. When writing my work, I begin by making a plan for drafting & Cognitive & 1 & .348 & .336 \\
the text & & & & \\
2. My school is a place where I feel excluded & Affective & - & - & -- \\
3. I am absent from school without a valid reason & Behavioral & 1 & .547 & .563 \\
4. During classes, I put questions to the teachers & Agency & 1 & .492 & .507 \\
5. I try to connect what I learn in one discipline with what I learn & Cognitive & 1.23 & .481 & .489 \\
in others & & & & \\
6. My school is a place where I make friends easily & Affective & 1 & .532 & .570 \\
7. I am absent from classes while in school & Behavioral & 1.13 & .593 & .587 \\
8. I talk to my teachers about my likes and dislikes & Agency & 0.92 & .393 & .378 \\
9. I spend a lot of my free time looking for information on topics & Cognitive & 1.41 & .512 & .483 \\
discussed in class & & & & \\
10. My school is a place where I feel integrated & Affective & 0.97 & .573 & .575 \\
11. I deliberately disturb classes & Behavioral & 1.24 & .643 & .629 \\
12. I comment with my teachers, when something interests me & Agency & 1.02 & .505 & .479 \\
13. When I'm reading, I try to understand the meaning of what & Cognitive & 1.30 & .576 & .546 \\
the author wants to transmit & & & & \\
14. My school is a place where it seems to me that others like & Affective & 1.04 & .589 & .615 \\
me & & & & \\
15. I am rude toward teachers & Behavioral & 1.20 & .669 & .632 \\
16. During lessons, I intervene to express my opinions & Agency & 0.99 & .466 & .458 \\
17. I review my notes regularly, even if a test is not coming up & Cognitive & 1.37 & .520 & .505 \\
18. My school is a place where I feel alone & Affective & -- & -- & -- \\
19. I am distracted in the classroom & Behavioral & 0.92 & .491 & .480 \\
20. I make suggestions to teachers about how to improve & Agency & 1.13 & .503 & .509 \\
classes & & & & \\
\hline Note: UE = Unstandardized Estimate; SEf = Standardized Estimate females; SEm = Standardized Estimate \\
\end{tabular}

Table 4. Variances, covariances and correlations among the engagement factors

\begin{tabular}{lllllllllll}
\hline Factors & \multicolumn{3}{c}{$\begin{array}{c}\text { Variances and } \\
\text { covariances }\end{array}$} & \multicolumn{3}{c}{$\begin{array}{c}\text { Correlations } \\
\text { females }\end{array}$} & \multicolumn{3}{c}{$\begin{array}{c}\text { Correlations } \\
\text { males }\end{array}$} \\
\cline { 2 - 12 } & F1 & F2 & F3 & F4 & F1 & F2 & F3 & F1 & F2 & F3 \\
\hline F1.Cognitive & 0.19 & & & & 1 & & & 1 & & \\
F2. Affective & 0.18 & 0.45 & & & .61 & 1 & & .63 & 1 & \\
F3. Behavioral & -0.06 & -0.10 & 0.37 & & -.20 & -.24 & 1 & -.23 & -.24 & 1 \\
F4. Agency & 0.18 & 0.18 & -0.01 & 0.31 & .78 & .50 & -.03 & .77 & .48 & -.03 \\
\hline & \multicolumn{3}{l}{ Note: All covariances and correlations statistically significant $(p<.05)$} & &
\end{tabular}


Table 5. Correlations of the four dimensions of school engagement with external criteria

\begin{tabular}{|c|c|c|c|c|}
\hline Criteria & $\begin{array}{l}\text { Cognitive } \\
\text { engagement }\end{array}$ & $\begin{array}{l}\text { Affective } \\
\text { engagement }\end{array}$ & $\begin{array}{l}\text { Behavioral } \\
\text { engagement }\end{array}$ & $\begin{array}{l}\text { Agency } \\
\text { engagement }\end{array}$ \\
\hline Engagement & .419 & .339 & -.159 & .352 \\
\hline Mastery orientation & $.262^{* x}$ & $.283^{* x}$ & $-.135^{x *}$ & $.243^{x \times}$ \\
\hline Performance orientation & $.205^{*}$ & $.184^{* *}$ & $.045^{*}$ & $.229^{* *}$ \\
\hline Mastery climate & $.261^{* *}$ & $.306^{*}$ & $-.121^{\star *}$ & $.214^{* *}$ \\
\hline Performance climate & $.103^{* *}$ & $.049^{*}$ & $.154^{* *}$ & $.088^{* *}$ \\
\hline Perceived autonomy support & $.344^{* *}$ & $.323^{\star x}$ & -.02 & $.321^{* x}$ \\
\hline School satisfaction & $.218^{\mathrm{x}}$ & $.239^{* x}$ & $-.087^{* \pi}$ & $.158^{* x}$ \\
\hline
\end{tabular}

scale results. In this regard, Veiga [15,12] presented such data for the SES-4DS in Portuguese samples, and his results shown a reliable scale, as well as reliable dimensions, with alphas always above .70. This is not in line with our results. Only the behavioral dimension had a relatively high alpha. Although dropping of two items in the affective dimension of engagement could well have affected the reliability of this factor, as measured by alpha, there is no straight explanation for the low reliabilities in the cognitive and agentic engagement factors.

Validity results were clearly in line with those found in the literature. Autonomy support is given when teachers promote the participation of the students into all the decision regarding academic tasks and school governance and allow for class discussion [49]. The relationship of these practices with school engagement may be explain as being practices that produce personal satisfaction and sense of responsibility with the school and learning environment [10,50]. Indeed correlational analyses have shown that students' classroom engagement was quite strongly and positively associated with teachers' autonomy support [51]. This research gives support to such findings with positive associations among the engagement dimensions and perceived autonomy support, with the exception of behavioral engagement.

Positive relationships among the engagement dimensions and motivational climate were also expected. Specifically, previous results have found that students who perceive their teachers' advance mastery goals are more motivated to learn and tend to engage in deeper cognitive processing, such as metacognitive and selfregulation strategies, than do students who report teachers with performance goals [52]. Thus, larger relations were expected between engagement and mastery climate promotion than it was expected for performance climate. This was indeed the case, as on one hand, there were positive relations of mastery climate with cognitive, affective and agentic engagement, and there were negative relations with behavioural engagement (misbehavior). On the other hand, the relationships among the engagement dimensions and performance climate were lower and positive in the particular case of behavioural engagement. The same pattern of results was found for students' mastery and performance orientation.

Finally, school satisfaction, defined as the "subjective, cognitive appraisal of the perceived quality of school life" [53, p. 210], was also significantly related to the dimensions of engagement (with the obvious negative relation with misbehavior). This was expected since as Noddings [27] argues, "children learn best when they are happy" (p. 2). This results provide some support for such notion.

Last but not least important have been the results on latent mean comparisons between males and females. The differences found at the latent mean level favoured males for cognitive and affective engagement, with no differences found in the other two dimensions. A recent trans-national study that studied gender differences in 12 countries across the world found larger means for females [54], which is contrary to in this study results.

\section{CONCLUSION}

With respect to the three aims of the study, the conclusions are:

a) Factorial validity was acceptable, with a structure of the expected four dimensions, but only after deleting two items in the affective dimension.

b) Scalar measurement invariance across gender has been supported by the data. 
c) The differences found at the latent mean level favored males for cognitive and affective engagement, with no differences found in the other two dimensions.

Among the limitations of the study, all variables included in the survey were self-report which can lead to some types of bias. Additionally, further research is clearly needed, both from a psychometric and a substantive point of view. Given the mixed results found in this research, replications in new samples of Angolan students and in new samples from other Portuguese speaking countries seem needed to clarify the structure, and the reliability of the scale. Given that the definition of behavioral engagement as a dimension measuring students' persistence, consistency of effort, concentration, determination, involvement in academic tasks and extracurricular activities, actions and practices related to school and learning [10], it could be interesting to avoid that all indicators in this dimension where measured as lack of behavioral engagement or misbehavior.

\section{COMPETING INTERESTS}

Authors have declared that no competing interests exist.

\section{REFERENCES}

1. Kuh GD, Kinzie J, Buckley JA, Bridges BK, Hayek JC. Piecing together the student success puzzle: Research, propositions, and recommendations. ASHE Higher Education Report. San Francisco: JosseyBass. 2007;32(5).

2. Martin AJ, Yu K, Papworth B, Ginns P, Collie RJ. Motivation and engagement in the United States, Canada, United Kingdom, Australia, and China: Testing a multi-dimensional framework. Journal of Psychoeducational Assessment. 2015; 33(2):103-114.

3. Appleton JJ, Christenson SL, Kim D, Reschly AL. Measuring cognitive and psychological engagement: Validation of the student engagement instrument. Journal of School Psychology. 2006; 44:427-445.

4. Fredricks JA, Blumenfeld PC, Paris AH. School engagement: Potential of the concept, state of the evidence. Review of Educational Research. 2004;74:59-109.

5. Lovelace MD, Reschly AL, Appleton JJ, Lutz ME. Concurrent and predictive validity of the student engagement instrument. Journal of Psychoeducational. 2014;32(6): 509-520.

6. Appleton JJ, Christenson SL, Furlong MJ. Student engagement with school: Critical conceptual and methodological issues of the construct. Psychology in the Schools. 2008;45:369-386.

7. Glanville JL, Wildhagen T. The measurement of school engagement: Assessing dimensionality and measurement invariance across race and ethnicity. Educational and Psychological Measurement. 2007;67(6):1019-1041.

8. Jimerson S, Campos E, Greif JL. Toward an understanding of definitions and measures of school engagement and related terms. California School Psychologist. 2003;8:7-27.

9. Reeve J. A self-determination theory perspective on student engagement. In SL Christenson, AL Reschly, C. Wylie (Eds.), Handbook of research on student engagement. New York: Springer; 2012.

10. Connell JP. Context, self and action: A motivational analysis of self-system processes across the life span. In $D$ Cicchetti, M Beeghly (Eds.), The self in transition: Infancy to childhood. Chicago: University of Chicago Press. 1990;61-97.

11. Reeve J, Tseng C. Personal agency as a fourth aspect of students' engagement during learning activities. Contemporary Educational Psychology. 2011;36:257-267.

12. Veiga $\mathrm{FH}$. Envolvimento dos alunos na escola: Elaboração de uma nova escala de avaliação. International Journal of Developmental and Educational Psychology. 2013;1(1):441-450.

13. Wang MT, Peck SC. Adolescent educational success and mental health vary across school engagement profiles. Developmental Psychology. 2013;49(7): 1266-1276.

14. Veiga FH. Disruptive Behavior Scale Professed by Students (DBS-PS): Development and validation. International Jour. of Psychology and Psychological Therapy. 2008;8:203-216.

15. Veiga FH. Proposal to the PISA of a new scale of students' engagement in school. Procedia - Social and Behavioral Sciences. 2012;46:1224-1231.

16. Archambault I, Janosz M, Fallu JS, Pagani LS. Student engagement and its relationship with early high school dropout. Journal of Adolescence. 2009;32:651-670. 
17. Sá L, Veiga FH. Aprendizagem e realização escolar dos jovens do ensino básico e secundário. Paper Presented at XVII Colóquio da AFIRSE/AIPELF: A escola e o mundo do trabalho, Lisboa, Portugal; 2009.

18. Motti-Stefanidi F, Masten A, Asendorpf JB. School engagement trajectories of immigrant youth: Risks and longitudinal interplay with academic success. International Journal of Behavioral Development. 2015;39(1):32-42.

19. O'Toole N, Due C. School engagement for academically at-risk students: A participatory research project. Australian Education Research. 2015;42:1-17.

20. Reeve J, Jang H, Carrell D, Jeon S, Barch J. Enhancing students' engagement by increasing teachers' autonomy support. Motivation and Emotion. 2004;28:147-169.

21. Patrick H, Kaplan A, Ryan AM. Positive classroom motivational environments: Convergence between mastery goal structure and classroom social climate. Journal of Educational Psychology. 2011;103(2):367-382.

22. Ames C. Classrooms: Goals, structures, and student motivation. Journal of Educational Psychology. 1992;84:261-271.

23. Kaplan A, Maehr ML. The contribution and prospects of goal orientation theory. Educational Psychology Review. 2007;19: 141-184.

24. Wang MT, Holcombe R. Adolescents' perceptions of school environment, engagement, and academic achievement in middle school. American Educational Research Journal. 2010;47(3):633-662.

25. Ladd GW, Buhs ES, Seid, M. Children's initial sentiments about kindergarten: Is school liking an antecedent of early classroom participation and achievement? Merrill-Palmer Quarterly. 2000;46:255-279.

26. Elmore GM, Huebner ES. Adolescents' satisfaction with school experiences: relationships with demographics, attachment relationships, and school engagement behavior. Psychology in the Schools. 2010;47(6):525-537.

27. Noddings N. Happiness and education. Cambridge, UK: Cambridge University Press; 2003.

28. Martin AJ. Enhancing student motivation and engagement: The effects of a multidimensional intervention. Contemporary Educational Psychology. 2008;33:239-269.
29. Johnson MK, Crosnoe R, Elder G. Students' attachment and academic engagement: The role of the race and ethnicity. Sociology of Education. 2001; 74:318-340.

30. Martin AJ. Examining a multidimensional model of student motivation and engagement using a construct validation approach. British Journal of Educational Psychology. 2007;77:413-440.

31. Betts JE, Appleton JJ, Reschly AL, Christensen SL, Scott-Huebner E. A study of the factorial invariance of the Student Engagement Instrument (SEI): Results from middle and high school students. School Psychology Quaterly. 2010;25: 84-93.

32. Wang M, Willet JB, Eccles JS. The assessment of school engagement: Examining dimensionality and measurement invariance by gender and race/ ethnicity. Journal of School Psychology. 2011;49:465-480.

33. Christenson SL, Reschly AL, Wylie C. Preface. In SL Christenson, AL Reschly, C Wylie (Eds.), Handbook of research on student engagement. NY: Springer; 2012.

34. Nie Y, Lau S. Complementary roles of care and behavioral control in classroom management: The self-determination theory perspective. Contemporary Educational Psychology. 2009;34:185-194.

35. Stornes EB, Bru E. Perceived motivational climates and self-reported emotional and behavioural problems among Norwegian secondary school students. School Psychology International. 2011;32: 425-438.

36. Jang $\mathrm{H}$, Kim EU, Reeve J. Longitudinal test of self-determination theory's motivation mediation model in a naturally occurring classroom context. Journal of Educational Psychology. 2012;104(4): 1175-1188.

37. Williams GC, Deci EL. Internalization of biopsychosocial values by medical students: A test of self-determination theory. Journal of Personality and Social Psychology. 1996;70(4):767-779.

38. Bentler PM. EQS structural equations program manual. Encino, CA: Multivariate Software, Inc; 1995.

39. Finney SJ, DiStefano C. Non-normal and categorical data in SEM. In GR Hancock, RO Mueller (Eds.), Structural equation modelling: A second course. Greenwich, 
CO: Information Age Publishing. 2006; 269-314.

40. Byrne B. Structural equation modeling with Mplus. New York: Routledge; 2012.

41. Millsap RE, Olivera-Aguilar M. Investigating measurement invariance using confirmatory factor analysis. In, $\mathrm{RH}$ Hoyle (Ed.), Handbook of structural equation modeling, New York, NY, US: Guilford Press. 2012;380-392.

42. Hu L, Bentler PM. Cut-off criteria for fit indexes in covariance structure analysis: Conventional criteria versus new alternatives. Structural Equation Modeling. 1999;6:1-55.

43. Tanaka JS. Multifaceted conceptions of fit in structural equation models. In K.A. Bollen \& J. S. Long (Eds.), Testing structural equation models. Newbury Park, CA: Sage. 1993;10-39.

44. Kline RB. Principles and practice of structural equation modelling. New York: Guilford; 1998.

45. Ullman JB. Structural equation modeling. In B. Tabachnick, \& L. Fidell (Eds.), Using multivariate statistics $\left(3^{\text {rd }}\right.$ ed.). NY: Harper Collins. 1996;709-812.

46. Bentler PM. Comparative fit indices in structural models. Psychological Bulletin. 1990;107:238-246.

47. Little TD. Mean and Covariance Structures (MACS) analyses of cross-cultural data: Practical and theoretical issues. Multivariate Behavioral Research. 1997;32: 53-76.

48. Cheung GW, Rensvold RB. Evaluating goodness-of-fit indexes for testing MI.
Structural Equation Modeling. 2002;9: 235-255.

49. Roeser RW, Eccles JS, Sameroff AJ. Academic and emotional functioning in early adolescence: Longitudinal relations, patterns, and prediction by experience in middle school. Development and Psychopathology. 1998;10:321-352.

50. Reeve J, Bolt E, Cai Y. Autonomysupportive teachers: How they teach and motivate students. Journal of Educational Psychology. 1999;91(3):537-548.

51. Jang $\mathrm{H}$, Reeve J, Deci EL. Engaging students in learning activities: It is not autonomy support or structure but autonomy support and structure. Journal of Educational Psychology. 2010;102(3): 588-600.

52. Pintrich PR. The role of goal orientation in self-regulated learning. In M. Boekaerts, P. R. Pintrich, \& M. Zeidner (Eds.), Handbook of self-regulation: Theory, research and application. San Diego, CA: Academic Press. 2000;451-502.

53. Baker JE, Dilly LJ, Aupperlee JL, Patil SA. The developmental context of school satisfaction: Schools as psychologically healthy environments. School Psychology Quarterly. 2003;18:206-221.

54. Lam S-f, Jimerson S, Kikas E, Cefai C, Veiga FH, Nelson B, Zollneritsch J. Do girls and boys perceive themselves as equally engaged in school? The results of an international study from 12 countries. Journal of School Psychology. 2012;50: 77-94.

(0) 2016 Gutiérrez et al.; This is an Open Access article distributed under the terms of the Creative Commons Attribution License (http://creativecommons.org/licenses/by/4.0), which permits unrestricted use, distribution, and reproduction in any medium, provided the original work is properly cited. http://sciencedomain.org/review-history/14170 